\title{
Deferral of Blood Donors Due To Anemia; an Experience of Blood Bank from Central India
}

\author{
Authors \\ Bhagwan Singh Yadav ${ }^{1}$, Prithviraj Singh ${ }^{2}$, Amit V Varma ${ }^{3}$, Rajesh Kumar \\ ${ }^{1}$ Assistant Professor Dept. of Pathology NSCB Medical College Jabalpur (MP) \\ Email: drbhagwan4@gmail.com Contact No 9893122118 \\ ${ }^{2}$ Assistant Professor Ekalavya Dental College Jaipur (RJ) \\ ${ }^{3}$ Professor and Head of Dept of Pathology, SAIMS Indore (MP) \\ ${ }^{4}$ Assistant Professor, Dept of Pharmacology NSCB Medical College Jabalpur (MP)
}

\begin{abstract}
The minimum haemoglobin $(\mathrm{Hb})$ cut-off for blood donation as per world blood transfusion standards is 12.5 $\mathrm{gm} / \mathrm{dl}$ for both male and female donors and the minimum donation interval is 3 months. Blood donation with haemoglobin levels less than $12.5 \mathrm{gm} / \mathrm{dl}$ can cause anaemia or deterioration of conditions of donor and deterioration of recipient condition because of low haemoglobin. Donation of one unit of blood results in decrease in haemoglobin by $1 \mathrm{gm} \%$ and loss of 200-250 $\mathrm{mg}$ of iron. Donor deferral due to anaemia is one of the major reasons of temporary rejection of blood donors. In the absence of further workup or advice, it results in loss of valuable donor base. This study is conducted to provide baseline information regarding the prevalence of anaemia in donor and assess distribution of donor according to socioeconomic status of donor. Haemoglobin screening of donors was performed using Copper sulphate specific gravity method. Venus blood sample of all the donors was tested on automated haematology analyser for confirmation of haemoglobin and evaluation of other haemogram parameters. In this study $6.7 \%$ donors were deferred due to anaemia $(<12.5 \mathrm{gm} / \mathrm{dl})$. Most of the donors $(>75 \%)$ belonged to middle socioeconomic group according to Prasad socio-economic scale (SES) scale.
\end{abstract}

Keywords: Donor deferral, haemoglobin, socioeconomic status.

\section{INTRODUCTION}

Haemoglobin $(\mathrm{Hb})$ screening is used for both to safeguard the health of potential donors and to ensure an adequate quality of blood products for recipients. According to world blood transfusion standards, potential donors should have haemoglobin levels over $12.5 \mathrm{gm} / \mathrm{dl}$ in order to be accepted as donors. Blood donation with haemoglobin levels less than $12.5 \mathrm{gm} / \mathrm{dl}$ can cause anaemia or deterioration of conditions that could lead to health problems in blood donors. In addition, the blood products from these donors are not of sufficient quality because of their low haemoglobin content ${ }^{[1]}$.

Blood donors are deferred due to several reasons, either temporarily or permanently. Deferrals can be characterized as temporary short term (1-56 days), long term (57-365 days), and multiple years/permanent (more than 365 days). ${ }^{[1]} \mathrm{A}$ large majority of the donor population in a developing country, like India, is deferred due to temporary but easily correctable cause-anaemia ${ }^{[2]}$. The causes of anaemia could be nutritional deficiency, anaemia due to blood loss, anaemia of chronic 
disease, and so on. Nutritional anaemia is a worldwide problem with the highest prevalence in developing countries like India. By far the most common cause of nutritional deficiency is iron deficiency. It can be either due to inadequate intake or poor bioavailability of dietary iron (only $5 \%-10 \%$ is absorbed) or due to excessive losses of iron from the body (malaria/hookworm infestation). Donor losses related to seropositivity for infectious markers are well established. Donor losses due to other reasons, however, have not been extensively quantified. The short-term temporary deferral due to anaemia can have a very negative impact on blood donor return rate and subsequent blood donations ${ }^{[2]}$.

In this study we aim to assess the prevalence of anaemia in our otherwise healthy donor population by estimating the frequency of donor deferral due to anaemia in central India Malwa (M.P.) region.

\section{MATERIALS AND METHODS}

The study was a prospective observational study conducted at blood bank for the duration of 12 months from June 2013 to May 2014. Prior to blood collection the donors were requested to answer a questionnaire to determine whether they are eligible for donation as per the criteria set by "NACO" along with their socio-economic status based on Prasad Prasad socio-economic scale (SES) scale. Both the first time and repeat donors were included in the study. The known seropositive donors for any of these infections (HIV, HBV,HCV, Syphilis, Malaria) and $\mathrm{Hb}$ less than $12.5 \mathrm{gm} \%$ were excluded. Informed consent was taken and the donors found unfit were deferred.

\section{Procedure (Specific Gravity Method):}

Five ml solution of $\mathrm{CuSO} 4$ (copper sulphate) with specific gravity 1.053 is taken in a clean glass tube. A drop of blood is allowed to fall from a height of $1 \mathrm{~cm}$ above the tube solution. If the drop is lighter than test solution it will rise only few $\mathrm{mm}$ and then sink slowly indicates $\mathrm{Hb}$ is $<12.5$ gm $\%$.
If the drop is heavier than test solution it will continue to fall within 10-15 seconds. It indicates $\mathrm{Hb}$ is $>12.5 \mathrm{gm} \%$. Donors which had Hemoglobin below $12.5 \mathrm{gm} \%$ were not accepted. All donors that were deferred due to $\mathrm{Hb}<12.5 \mathrm{gm} / \mathrm{dl}$, confirmation of $\mathrm{Hb}$ was done by running venous EDTA samples on automated hematology analyzer (Sysmex KY21hematology analyzer)and other CBC Parameters were assessed along with peripheral smear examination.

\section{RESULT AND DISCUSSION}

Majority of the donors in this study were males which is comparable to the studies done by others. We observed that out of the total 5000donors the female donors comprised only $65(1.30 \%)$ the remaining $4935(98.70 \%)$ were male donors. Arora et $\mathrm{al}^{[3]}$ in Southern Haryana, Singh K et al ${ }^{[4]}$ in Coastal Karnataka, Pahuja et al ${ }^{[5]}$ in Delhi and Singh B et al ${ }^{[6]}$ observed more than $90 \%$ male donors out of the total donor population.

In present study, we observed a predominance of replacement donors that were $3686(92 \%)$ as found by Singh et $\mathrm{al}^{[6]}(82.4 \%)$, Kakkar et $\mathrm{al}^{[7]}(94.7 \%)$, Pahuja et al ${ }^{[5]}(99.48 \%)$ and Arora et al $(68.6 \%)^{[3]}$ whereas study done by Richa Gupta et $\mathrm{al}^{[8]}$ has shown $39.71 \%$ voluntary donors \& $60.22 \%$ replacement donors.

A total of 5000 donors came to blood bank during study period out of which total $12 \%$ (600) donors were deferred for various reasons. Among total deferred donors, $55.84 \%$ (335) donors were deferred due to anemia $(\mathrm{Hb}<12.5 \mathrm{gm} \%)$.Thus prevalence of anemia among total donors in our study was $6.7 \%$. Microcytic hypochromic anemia constituted $69.85 \%$ (234 donors), most common type of anemia among deferred donors.

In our study, the percentage of donors deferred due to anemia was estimated to be $6.7 \%$. This is in accordance with blood donor deferral rates found in the literature, which range from $3 \%$ to $15 \%$ [9${ }^{11]}$.In a blood donation program where the majority of blood donors were first time donors is also a reflection of the prevalence of anemia in the adult population in the community. The 
prevalence of anemia in our study population was lower than reported in our general population, probably as majority of our donors were adult males $(98.70 \%)^{[12]}$. Conventional screening programs based on hemoglobin are adequate to prevent the development of progressive iron deficiency anemia; they provide no indication of the development of tissue iron depletion. Recent literature has suggested that serum ferritin levels appear to be a reliable indicator for body iron stores that can be mobilized and provide reliable measurements for determining iron deficiency at an early stage ${ }^{[13]}$ Currently there are no guidelines for management of these deferred donors. This results in loss of valuable part of donor pool who can donate blood if advised and treated appropriately for anemia. Studies indicate that ferrous sulphate supplementation therapy can be considered as one of the strategies to promote safe blood donation in woman ${ }^{[14]}$.

As far as the socioeconomic status of the donors at our blood bank is concerned, Most of the donors were from the middle socio-economic group as per the Prasad SES scale. We observed that of the 5000: donors 500 donors were of SES class I(10\%), $2000(40 \%)$ were in SES II, 1750 $(35 \%)$ in SES III,4 30 were in $\operatorname{SES~IV(8.6\% )~\& ~}$ SES V 320 cases $(6.4 \%)$. (Figure no.-1)
This is in accordance with the patient population visiting the hospital which caters to the surrounding rural belt and middle income group of (Indore) Malwa region.

Our results show that different socio-economic donor profiles can be distinguished. One of the factors favouring repeat blood donation by a donor is a higher socioeconomic status as their $\mathrm{Hb}$ level permit repeat donation. Various studies have indicated severity of anaemia in lower socioeconomic strata limiting repeat blood donations $^{[9,13-14]}$.

\section{CONCLUSION}

In our present study the number of donors with $\mathrm{Hb}$ lower than $12.5 \mathrm{gm} \%$ were $6.7 \%$.This indicates that donor selection has to be stringent and screening for $\mathrm{Hb}$ by copper sulphate method is effective in avoiding blood donors with a lower $\mathrm{Hb}$ level as anaemia is rampant in India and many patients are well compensated and are asymptomatic clinically. The majority of donors in our blood bank comprise of middle socioeconomic class as our catchment area is comprising of mainly rural population with a modest level of incomes and a middle level of education.

Figure -1 Distribution of donor according to socioeconomic status as per the Prasad SES scale

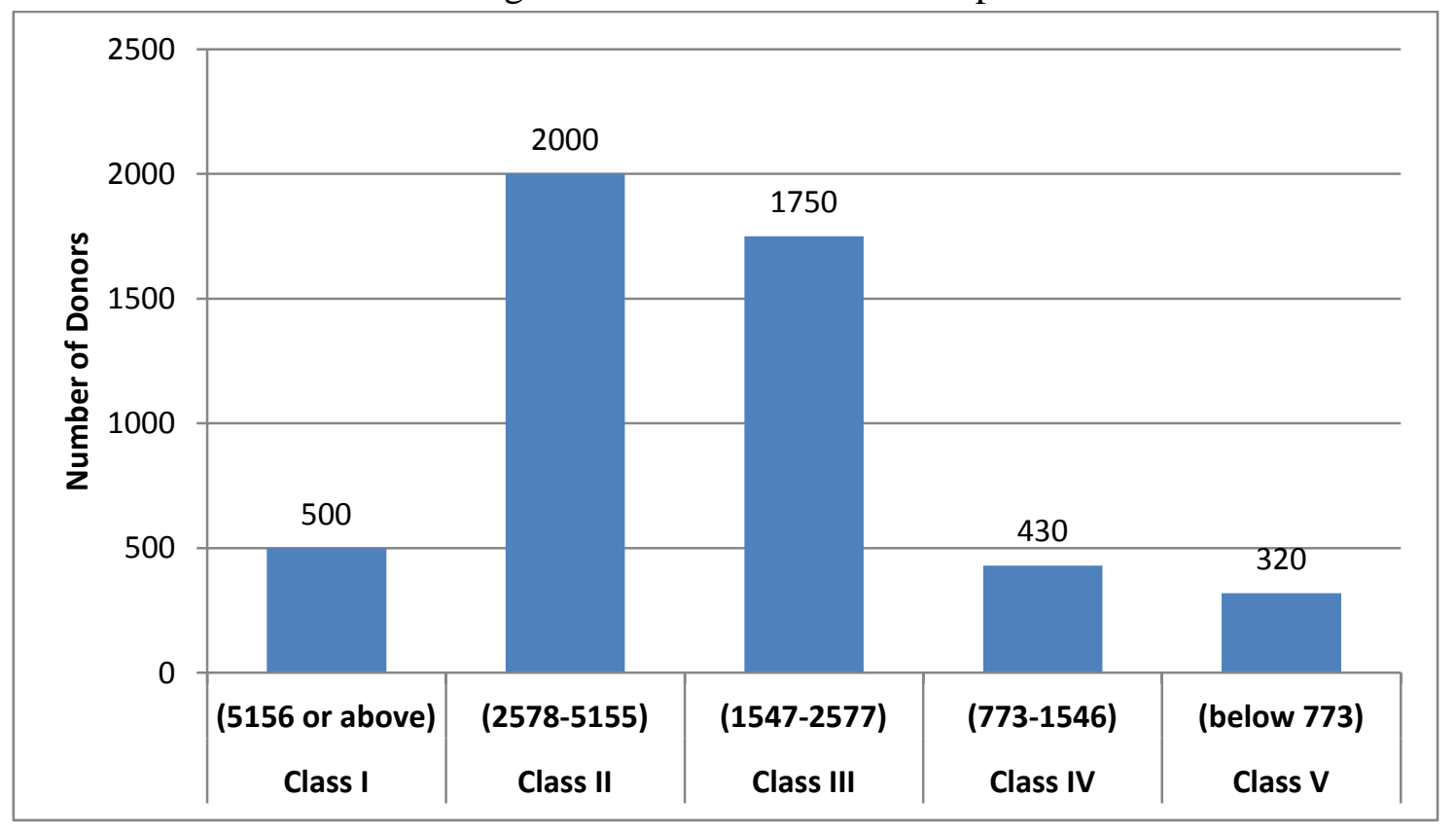




\section{REFERENCE}

1. ShahshahaniH J,Meraat N,Mansouri F Evaluation of the validity of a rapid method for measuring high and low haemoglobin levels in whole blood donors; BloodTransfus. 2013: 11: 385-90

2. Bahadur S, Pujani M, Jain M. Donor deferral due to anemia: A tertiary care centre-based study; Asian Journal of Transfusion Science. 2011 Jan-June; 5(1):53-55.

3. Arora D, Arora B, Khetarpal A. Seroprevalence of HIV, HBV, HCV and syphilis in blood donors in Southern Haryana. Indian

PatholMicrobiol. 2010:53:308-309.

4. Singh K, Bhat S, ShastryS.Trend in seroprevalence of Hepatitis B virus infection among blood donors of coastal Karnataka, India. J Infect DevCtries. 2009:3:376-379.

5. Pahuja S, Sharma M, Baitha B, Jain M. Prevalence and trends of markers of hepatitis $\mathrm{C}$ virus, hepatitis $\mathrm{B}$ virus and human immunodeficiency virus in Delhi blood donors. A hospital based study. Jpn J Inf Dis. 2007:60:389-391.

6. Singh B, Verma M, Kotru M, Verma K, Batra M. Prevalence of HIV and VDRL seropositivity in blood donors of Delhi. Indian J Med Res. 2005:122:234236

7. Kakkar N, Kaur R, Dhanoa J. voluntary donors-need for a second look. Indian $\mathrm{J}$ Pathol Microbiol. 2004:47:381-383

8. GuptaR,Singh B, KumarD, Chugh M. Prevalence and trends of transfusion transmitted infections in a regional blood transfusion centre; Asian J Transfus Sci. 2011 Jul-Dec; 5(2): 177-178.

9. Sunder P, Vivekanand J. Anemia in blood donors in Bangalore. Tranfus Bull. 2009:29.
10. Deb R, Chaya S, Bharucha Z. Evaluation of methods for haemoglobin estimations in blood donor screening. Indian J Hematol Blood Transfus. 2002:20:25-7.

11. Elhence P, Pandey P, Chaudhary RK. Blood donor deferral due to anemia: Need for investigation. Indian J Hematol Blood Transfus 2007:33:25-8.

12. Ramesh Chellan, Lopamudra Paul. Prevalence of Iron-Deficiency Anaemia in India: Results from a Large Nationwide Survey.Journal of population and social studies. 2010 July;19 (1).

13. Rudolfo DC, Carlos SC, Fausto FA, Dante MLJ, Rita de CS. Iron deficiency in blood donors. Sao Paulo Med J. 2001:119:132-4.

14. Maghsudlu M, Nasizadeh S, Toogeh GR, Zandieh T, Parandoush S, Rezayani M. Short term ferrous sulphate supplementation in female blood donors, Transfusion. 2008:48:1192-7. 